\title{
Patient positioning during percutaneous nephrolithotomy: what is the current best practice?
}

This article was published in the following Dove Press journal: Research and Reports in Urology

\section{Panagiotis Mourmouris Marinos Berdempes \\ Titos Markopoulos \\ Lazaros Lazarou \\ Lazaros Tzelves \\ Andreas Skolarikos}

Second Department of Urology, Athens Medical School, National and Kapodistrian University of Athens, Sismanogleio General Hospital, Athens, Greece
Correspondence: Panagiotis Mourmouris Second Department of Urology, Athens Medical School, National and Kapodistrian University of Athens, Sismanogleio General Hospital, Ist Sismanogleiou Street, Maroussi, I5I 26 Athens, Greece

Tel +30 2l 32058102

Email thodoros13@yahoo.com

\begin{abstract}
Percutaneous nephrolithotomy (PCNL) is the gold standard procedure for treatment of large stones and complex kidney disorders, but its morbidity remains the highest among stone treatment procedures. In pursuit of minimizing complication rates, surgeons have developed different variations of the classic prone position in which PCNL is usually performed; one among them is supine position. In this study, we review the literature and present all available evidence on different variations in positioning during PCNL, in an effort to identify if there is a position that can minimize the morbidity of this procedure.
\end{abstract}

Keywords: percutaneous nephrolithotomy, prone, supine, complications

\section{Introduction}

Soon after percutaneous nephrolithotomy (PCNL) was included in the urologists' toolkit, it became the gold standard procedure for treatment of large $(>2 \mathrm{~cm})$ renal stones; moreover, it is an important alternative for treatment of lower pole (even $<1.5 \mathrm{~cm}$ ) and complex stones and anatomic abnormalities of the kidneys. ${ }^{1}$ Despite increased experience, acquired through many years of use, the morbidity of PCNL remains the highest among stone treatment procedures. ${ }^{2,3}$ In pursuit of minimizing complication rates, many surgeons embarked on a journey of improving this old procedure. Since prone positioning was the standard positioning for performing PCNL, contributing at the same time to increased morbidity, mainly due to cardiac and respiratory encumbrance, ${ }^{4}$ our study mainly focused on patient positioning during PCNL. This quest, which began with the introduction of the supine position but Valdivia et al., ${ }^{5}$ resulted in many variations of patient positioning, each one of which having its own advantages and disadvantages. In our study, we review the literature and present all available evidence on different variations in positioning during PCNL in an effort to identify if there is a position that can make minimize the morbidity of this procedure.

\section{Methods}

Our study included articles in English language, indexed in the Medline database from 1990 to 2018. Our search mainly focused on meta-analyses, systematic reviews and randomized controlled trials (RCTs) to obtain a high level of evidence. The key words that were used during our search were PCNL, complication rates, positioning, prone and supine. Case reports and series and editorials were excluded from our study. 


\section{Positioning}

Percutaneous nephrolithotripsy was introduced to urologists through the pioneer work of two surgical teams, Fernstrom et al and Castaneda-Zuniga et al, who performed PCNL in the classic prone position and reported excellent results with minimal complication rates. ${ }^{6,7}$ Since then, PCNL has become the golden standard procedure for treatment of large or staghorn kidney stones and all surgeons have positioned their patients in the prone position without any deviations. It took surgeons more than 12 years to start practicing various modifications of the classic prone position. Through their work, modified prone positions were introduced including, but not limited to, reverse lithotomy position, ${ }^{8}$ prone split leg position ${ }^{9}$ and prone flexed position. ${ }^{10}$ All the above techniques require turning the patient to the prone position with several risks including cervical spine injury and skeletal or eye complications ${ }^{11}$ that require extreme care in the alignment of the patient in the most neutral position. The need to deal with the aforementioned drawbacks, along with the anesthesiology considerations, incites surgeons to develop novel positions, and the first team to report one such position was Valdivia Uría et al as early as 1987 which is called supine position. ${ }^{5}$ As expected, many surgeons modified this position and published their results, with Galdakao-modified Valdivia position, Barts technique, complete supine position and Barts flank-free modified position being among the most popular modifications. ${ }^{12-15}$ One of the practical advantages of the prone technique is the easier identification of the correct calyx while theoretically minimizing injuries of adjacent structures, whereas the main hypothetical advantage of the supine position is the minimization of cardiac and respiratory encumbrance and the easier puncture of the upper calyx. ${ }^{16} \mathrm{In}$ addition, one of the most important advantages of the supine position is that it allows to simultaneously perform retrograde intrarenal surgery (RIRS). This surgery can be routinely performed in the supine-modified positions such as Galdakaomodified Valdivia position, Barts-modified Valdivia position and Barts flank-free modified postition. ${ }^{12-15}$ Nevertheless in the first two techniques, performing RIRS simultaneously with the percutaneous procedure is challenging and requires experience, because the rotation of the trunk produces a relatively unfamiliar position for ureteroscopy. ${ }^{17}$ In addition, it is important to stress that despite the common belief, the percutaneous procedure in complete supine position, cannot be easily combined with RIRS due to the fact that legs will not be in the lithotomy position. ${ }^{17}$

\section{Stone-free rate}

PCNL is a stone management surgery; therefore, inevitably, the two positions, supine and prone, will be compared in terms of their efficacy on the main target: stone-free rate. The above-mentioned comparison was the goal of several meta-analyses with conflicting evidence. Two of them found statistically significant difference in favor of the prone position, ${ }^{18,19}$ while two failed to prove any difference between the two techniques (OR $0.95 ; 95 \%$ CI: $0.70-1.27 ; P=0.73$ )..$^{20,21}$ Nevertheless, even in the above-mentioned studies that found differences between the two procedures, this difference was in a range of $3 \%-5 \%$. It is important to emphasize that the meta-analysis of Falahatkar et al, which included more than 4,335 patients from 20 studies (most of them were RCTs and prospective trials), provides the best level of evidence, since the evaluation of the included studies showed that most of them were of high quality. ${ }^{20}$ The meta-analyses by Yuan et a ${ }^{18}$ and Zhang et a ${ }^{19}$ provide a good assessment of the quality of the included studies, and despite the fact that they included lesser RCTs, their funnel plot was symmetrical which indicates low publication bias. Finally, the meta-analysis of Liu et $\mathrm{al}^{21}$ used a different tool for the assessment of RCTs and observational studies; however, there are no information about their publication data, which may have compromised their outcomes and quality.

\section{Complication rate}

Minimizing morbidity was the main goal of the introduction of supine positioning in PCNL. Initial reports were very promising in terms of complication rates, which fluctuated between $14 \%$ and $20 \%$ with minimal rates of serious complications. ${ }^{22-25}$ Nevertheless, the most recent meta-analysis does not support this finding. Comparing prone and supine positions, researchers failed to prove any statistically significant difference in terms of overall complication rates. ${ }^{18-21}$ Furthermore, rates of pleural effusion ${ }^{26-29}$ and urinary leakage, ${ }^{30-33}$ surprisingly, do not seem to differ between the two techniques. However, a trend of higher fever rates in favor of the supine position has been shown in one of the studies. ${ }^{18}$ In addition, injury to the bowel, even though an uncommon complication, has been the point of comparison between the two techniques for a long time. Most recent studies seem to clarify this important controversial issue, since the rate of colonic injury was found to be $<0.3 \%$ in the prone position, ${ }^{34,35}$ whereas when compared to the supine position, no statistically significant difference was proven $(3.3 \%$ vs $3.4 \%$, $P=0.958){ }^{28}$

\section{Intraoperative and postoperative outcomes}

Even though the prone and supine techniques do not seem to differ in the main end points, differences in the length of stay, 
duration of the operation and blood transfusion could potentially alter the final verdict. In a recent study comparing prone and supine positions, operation time was significantly longer for the prone group (68.7 vs 54.2 minutes; $P=0.04$ ), whereas the mean hospital stay was not significantly different between the groups ( 2.6 vs 2.9 days; $P=0.9$ ), as was the case with the blood transfusion rates $(P=0.7) .{ }^{36}$ The study of McCahy et al yielded similar results, with the supine position gaining superiority over the prone position in terms of operation time, while no difference was proven in terms of hospital stay and blood transfusion rates. ${ }^{37}$ Again, the results of the available meta-analyses should aid in determining if one of the techniques is superior over the other. Although data from all four meta-analyses seem to agree on hospital stay, which is reported as equal between the two techniques, this is not the case with operation time and blood transfusion rates, for which the data are controversial. ${ }^{18-21}$ In one of these meta-analyses, data imply that supine position is characterized by lower blood transfusions ${ }^{17}$ and less operative time. ${ }^{18,19,21}$ In contrast, in the large and most organized metaanalysis, the authors state that the two positions do not differ in operation time. ${ }^{20}$ Prone technique requires 20-25 minutes to place the patient in a safe position, and it has, as mentioned before, a $3 \%-5 \%$ better stone-free rate. It is under debate whether this advantage is worth the delay.

\section{Anesthesiology considerations}

One of the main drawbacks of the prone position is supposed to be the encumbrance of the respiratory system and the difficulties that the anesthesiologist needs to address. Even though this is one of the main reasons for developing the supine position, only scarce data exist in literature addressing this important issue. The most pronounced difficulty during prone positioning is maintaining an easy and optimal access to the airway tube and minimizing the risk of its displacement. In addition, anesthesiology factors, like peak inspiratory pressure, blood pressure and heart rate, could theoretically be altered during prone positioning, especially in obese patients, but researchers do not seem to agree with this assumption: even though obese patients have higher baseline peak inspiratory pressure, this does not depend on the patient's position. ${ }^{38}$ In addition to the aforementioned anesthesiology difficulties associated with the pulmonary and cardiovascular system, there is an increased possibility of cervical spine injury and several other skeletal complications during the patient's repositioning. Nevertheless, there are reports in literature that awake intubation and selfpositioning of the patients before the induction of anesthesia can minimize the above-mentioned risks. ${ }^{39,40}$

\section{Obesity and special conditions}

Obesity is a major issue in most surgeries, and PCNL is not an exception. There are numerous reports that prove the efficacy and safety of PCNL even in patients with a body mass index $\geq 50 \mathrm{~kg} / \mathrm{m}^{2}{ }^{41-43}$ Most surgeons seem to prefer prone position over supine for obese patients, most likely due to the longer tract that increased subcutaneous fat produces. ${ }^{44}$ Despite the absence of RCTs comparing these two approaches, there are reports proving that prone and supine techniques have no advantage over each other in terms of stone-free and complication rates. ${ }^{45}$ For special conditions, the operation technique must be personalized: horseshoe kidneys may require prone access due to the anatomic placement of the upper calyces, ${ }^{46,47}$ while patients with pelvic kidneys should be approached in supine position. ${ }^{48}$ The advantages and disadvantages of each technique are shown in Table 1.

\section{Miniaturization}

An important topic to address is whether miniaturization affects the outcomes of the procedure comparing between

Table I Advantages and disadvantages of each position

\begin{tabular}{|c|c|c|}
\hline & Advantages & Disadvantages \\
\hline Prone & $\begin{array}{l}\text { I. Easy puncture } \\
\text { 2. Routine dilatation with short tracts } \\
\text { 3. Multiple punctures easier due to large operative field } \\
\text { 4. Easier access in morbid obese patients } \\
\text { 5. Preferred in horseshoe kidneys }\end{array}$ & $\begin{array}{l}\text { I. No or difficult synchronous RIRS } \\
\text { 2. } 20-25 \text { minutes more for a safe positioning } \\
\text { 3. Challenging position for the anesthetist } \\
\text { 4. Require patient repositioning (may } \\
\text { increase rates of spine and skeletal injury) }\end{array}$ \\
\hline Supine & $\begin{array}{l}\text { I. Synchronous RIRS (in some modified positions) } \\
\text { 2. Routine position for anesthetist } \\
\text { 3. No patient repositioning } \\
\text { 4. Lesser time (in some studies) } \\
\text { 5. Preferred in pelvic kidneys } \\
\text { 6. No requirement for fluoroscopy }\end{array}$ & $\begin{array}{l}\text { I. Longer tracts (after dilatation) } \\
\text { 2. Difficult dilatation due to increased } \\
\text { mobility of kidneys (Valdivia) } \\
\text { 3. Limited operation field } \\
\text { 4. Difficult puncture due to torso rotation } \\
\text { (Galdakao-modified Valdivia) }\end{array}$ \\
\hline
\end{tabular}

Abbreviation: RIRS, retrograde intrarenal surgery. 
prone and supine positions. The data in the literature concerning this subject are very limited. The main end point of a relatively recent study, enrolling more than 150 patients, was to compare the outcomes of mini-PCNL performed in these two positions. The authors failed to prove any statistically significant difference between the two approaches in terms of stone-free rates, complication rates and hospital stay but there was a trend of longer operation time in prone position. ${ }^{49}$

\section{Conclusion}

All data in literature point out that the supine position is a safe and efficient alternative to prone position, but its advantage over the prone position is far from proven. Supine position and its modifications provide a minor advantage in terms of operation time, but it is not superior to prone position in terms of other critical factors such as stone-free, complication and transfusion rates. We recommend that the choice of the appropriate approach be based on the surgeon's experience, the patient's preference and the consideration of all the basic anatomic and physiological data of the patient.

\section{Disclosure}

The authors report no conflicts of interest in this work.

\section{References}

1. Türk C, Petř́k A, Sarica K, et al. EAU Guidelines on interventional treatment for urolithiasis. Eur Urol. 2016;69(3):475-482.

2. Jackman SV, Hedican SP, Peters CA, Docimo SG. Percutaneous nephrolithotomy in infants and preschool age children: experience with a new technique. Urology. 1998;52(4):697-701.

3. Knoll T, Heger K, Haecker A. Percutaneous nephrolithotomy: experience from 348 procedures. Eur Urol. 2004;3:42.

4. Bozzini G, Verze P, Arcaniolo D, et al. A prospective randomized comparison among SWL, PCNL and RIRS for lower calyceal stones less than $2 \mathrm{~cm}$ : a multicenter experience : A better understanding on the treatment options for lower pole stones. World J Urol. 2017;35(12):1967-1975.

5. Valdivia Uría JG, Lachares Santamaría E, Villarroya Rodríguez S, Taberner Llop J, Abril Baquero G, Aranda Lassa JM. Percutaneous nephrolithectomy: simplified technic (preliminary report). Arch Esp Urol. 1987;40(3):177-180.

6. Fernstrom I, Johansson B, Pyelolithotomy P. A new extraction technique. Scand J Urol Nephrol. 1976;10(3):257-259.

7. Castaneda-Zuniga WR, Clayman R, Smith A, Rusnak B, Herrera M, Amplatz K. Nephrostolithotomy: percutaneous techniques for urinary calculus removal. AJR Am J Roentgenol. 1982;139(4):721-726.

8. Lehman T, Bagley DH. Reverse lithotomy: modified prone position for simultaneous nephroscopic and ureteroscopic procedures in women. Urology. 1988;32(6):529-531.

9. Grasso M, Nord R, Bagley DH. Prone split leg and flank roll positioning: simultaneous antegrade and retrograde access to the upper urinary tract. J Endourol. 1993;7(4):307-310.

10. Ray AA, Chung DG, Honey RJ. Percutaneous nephrolithotomy in the prone and prone-flexed positions: anatomic considerations. JEndourol. 2009;23(10):1607-1614.
11. Pakravan M, Kiavash V, Moradian S. Posterior Ischemic Optic Neuropathy Following Percutaneous Nephrolithotomy. J Ophthalmol. 2006;11(4):558-563.

12. Ibarluzea G, Scoffone CM, Cracco CM, et al. Supine Valdivia and modified lithotomy position for simultaneous anterograde and retrograde endourological access. BJU Int. 2007;100(1):233-236.

13. Papatsoris AG, Zaman F, Panah A, Masood J, El-Husseiny T, Buchholz N. Simultaneous anterograde and retrograde endourologic access: "the Barts technique". J Endourol. 2008;22(12):2665-2666.

14. Bach C, Goyal A, Kumar P, et al. The Barts "flank-free" modified supine position for percutaneous nephrolithotomy. Urol Int. 2012;89(3):365-368.

15. Falahatkar S, Asli MM, Emadi SA, Enshaei A, Pourhadi H, Allahkhah A. Complete supine percutaneous nephrolithotomy (csPCNL) in patients with and without a history of stone surgery: safety and effectiveness of csPCNL. Urol Res. 2011;39(4):295-301.

16. Sofer M, Giusti G, Proietti S, et al. Upper calyx approachability through a lower calyx access for prone versus supine percutaneous nephrolithotomy. J Urol. 2016;195(2):377-382.

17. Kumar P, Bach C, Kachrilas S, et al. Supine percutaneous nephrolithotomy (PCNL): "in vogue" but in which position? BJU Int. 2012;110(11 Pt C):E1018.

18. Yuan D, Liu Y, Rao H, et al. Supine Versus Prone Position in Percutaneous Nephrolithotomy for Kidney Calculi: A Meta-Analysis. J Endourol. 2016;30(7):754-763.

19. Zhang X, Xia L, Xu T, Wang X, Zhong S, Shen Z. Is the supine position superior to the prone position for percutaneous nephrolithotomy (PCNL)? Urolithiasis. 2014;42(1):87-93.

20. Falahatkar S, Mokhtari G, Teimoori M. An Update on Supine Versus Prone Percutaneous Nephrolithotomy: A Meta-analysis. Urol J. 2016;13(5):2814-2822.

21. Liu L, Zheng S, Xu Y, Wei Q. Systematic review and meta-analysis of percutaneous nephrolithotomy for patients in the supine versus prone position. J Endourol. 2010;24(12):1941-1946.

22. Falahatkar S, Allahkhah A, Soltanipour S. Supine percutaneous nephrolithotomy: pro. Urol J. 2011;8(4):257-264.

23. Falahatkar S, Kazemnezhad E, Moghaddam KG, et al. Middle calyx access in complete supine percutaneous nephrolithotomy. Can Urol Assoc J. 2013;7(5-6):306-310.

24. Falahatkar S, Moghaddam KG, Kazemnezhad E, et al. Factors affecting complications according to the modified Clavien classification in complete supine percutaneous nephrolithotomy. Can Urol Assoc J. 2015;9(1-2):83-92.

25. Karami H, Rezaei A, Mohammadhosseini M, Javanmard B, Mazloomfard M, Lotfi B. Ultrasonography-guided percutaneous nephrolithotomy in the flank position versus fluoroscopy-guided percutaneous nephrolithotomy in the prone position: a comparative study. J Endourol. 2010;24(8):1357-1361.

26. Sanguedolce F, Breda A, Millan F, Brehmer M, Knoll T. Lower pole stones: prone PCNL versus supine PCNL in the International Cooperation in Endourology (ICE) group experience. 2013;31(6):1575-1580.

27. Al-Dessoukey AA, Moussa AS, Abdelbary AM, et al. Percutaneous nephrolithotomy in the oblique supine lithotomy position and prone position: a comparative study. J Endourol. 2014;28(9):1058-1063.

28. Valdivia JG, Scarpa RM, Duvdevani M, et al. Supine versus prone position during percutaneous nephrolithotomy: a report from the clinical research office of the endourological society percutaneous nephrolithotomy global study. J Endourol. 2011;25(10):1619-1625.

29. Mazzucchi E, Vicentini FC, Marchini GS, et al. Percutaneous nephrolithotomy in obese patients: comparison between the prone and total supine position. J Endourol. 2012;26(11):1437-1442.

30. Amon Sesmero JH, del Valle Gonzalez N, Conde Redondo C, et al. Comparison between Valdivia position and prone position in percutaneous nephrolithotomy. ActasUrolEsp. 2008;32(4):424-429.

31. Falahatkar S, Moghaddam AA, Salehi M, Nikpour S, Esmaili F, Khaki N. Complete supine percutaneous nephrolithotripsy comparison with the prone standard technique. J Endourol. 2008;22(11):2513-2518. 
32. de Sio M, Autorino R, Quarto G, et al. Modified supine versus prone position in percutaneous nephrolithotomy for renal stones treatable with a single percutaneous access: a prospective randomized trial. Eur Urol. 2008;54(1):196-203.

33. Shoma AM, Eraky I, El-Kenawy MR, El-Kappany HA. Percutaneous nephrolithotomy in the supine position: technical aspects and functional outcome compared with the prone technique. Urology. 2002;60(3):388-392.

34. Aslzare M, Darabi MR, Shakiba B, Mahtaj LG, Gholami-Mahtaj L. Colonic perforation during percutaneous nephrolithotomy: An 18-year experience. Can Urol Assoc J. 2014;8(5-6):323-326.

35. El-Nahas AR, Shokeir AA, El-Assmy AM, et al. Colonic perforation during percutaneous nephrolithotomy: study of risk factors. Urology. 2006;67(5):937-941.

36. Karami H, Mohammadi R, Lotfi B. A study on comparative outcomes of percutaneous nephrolithotomy in prone, supine, and flank positions. World J Urol. 2013;31(5):1225-1230.

37. Mccahy P, Rzetelski-West K, Gleeson J. Complete stone clearance using a modified supine position: initial experience and comparison with prone percutaneous nephrolithotomy. J Endourol. 2013;27(6):705-709.

38. Siev M, Motamedinia P, Leavitt D, et al. Does Peak Inspiratory Pressure Increase in the Prone Position? An Analysis Related to Body Mass Index. J Urol. 2015;194(5):1302-1307.

39. Heng L, Wang MY, Sun HL, Zhu SS. Awake nasotracheal fiberoptic intubation and self-positioning followed by anesthesia induction in prone patients: A pilot observational study. Medicine. 2016;95(32):e4440.

40. Wu SD, Yilmaz M, Tamul PC, Meeks JJ, Nadler RB. Awake endotracheal intubation and prone patient self-positioning: anesthetic and positioning considerations during percutaneous nephrolithotomy in obese patients. J Endourol. 2009;23(10):1599-1602.
41. Koo BC, Burtt G, Burgess NA. Percutaneous stone surgery in the obese: outcome stratified according to body mass index. BJU Int 2004;93(9):1296-1299.

42. Keheila M, Leavitt D, Galli R, et al. Percutaneous nephrolithotomy in super obese patients (body mass index $\geq 50 \mathrm{~kg} / \mathrm{m}^{2}$ ): overcoming the challenges. BJU Int. 2016;117(2):300-306.

43. Zhou X, Sun X, Chen X, et al. Effect of obesity on outcomes of percutaneous nephrolithotomy in renal stone management: a systematic review and meta-analysis. Urol Int. 2017;98(4):382-390.

44. Fuller A, Razvi H, Denstedt JD, et al. The clinical research office of the endourological society percutaneous nephrolithotomy global study: Outcomes in the morbidly obese patient - a case control analysis. Can Urol Assoc J. 2014;8(5-6):393-397.

45. Torrecilla Ortiz C, Meza Martínez AI, Vicens Morton AJ, et al. Obesity in percutaneous nephrolithotomy. Is body mass index really important? Urology. 2014;84(3):538-543.

46. Shokeir AA, El-Nahas AR, Shoma AM, et al. Percutaneous nephrolithotomy in treatment of large stones within horseshoe kidneys. Urology. 2004;64(3):426-429.

47. El Ghoneimy MN, Kodera AS, Emran AM, Orban TZ, Shaban AM, El Gammal MM. Percutaneous nephrolithotomy in horseshoe kidneys: is rigid nephroscopy sufficient tool for complete clearance? A case series study. BMC Urol. 2009;9:17.

48. Otaño N, Jairath A, Mishra S, Ganpule A, Sabnis R, Desai M. Percutaneous nephrolithotomy in pelvic kidneys: is the ultrasound-guided puncture safe? Urology. 2015;85(1):55-58.

49. Tokatlı Z, Gokce MI, Süer E, Sağlam R. Supine or prone position for mini-PNL procedure: does it matter. Urolithiasis. 2015;43(3) 261-264.
Research and Reports in Urology

\section{Publish your work in this journal}

Research and Reports in Urology is an international, peer-reviewed, open access journal publishing original research, reports, editorials, reviews and commentaries on all aspects of adult and pediatric urology in the clinic and laboratory including the following topics: Pathology, pathophysiology of urological disease; Investigation and treatment of

\section{Dovepress}

urological disease; Pharmacology of drugs used for the treatment of urological disease. The manuscript management system is completely online and includes a very quick and fair peer-review system, which is all easy to use. Visit http://www.dovepress.com/testimonials.php to read real quotes from published authors. 